\title{
Methods for Human-Computer Interaction Research
}

\begin{abstract}
Sandy J.J. Gould
UCL Interaction Centre

University College London

s.gould@cs.ucl.ac.uk
\end{abstract}

Duncan P. Brumby

UCL Interaction Centre

University College London

brumby@cs.ucl.ac.uk

Anna L. Cox

UCL Interaction Centre

University College London

anna.cox@ucl.ac.uk

\author{
Geraldine Fitzpatrick \\ Human Computer Interaction Group \\ Vienna University of Technology \\ geraldine.fitzpatrick@tuwien.ac.at \\ Jettie Hoonhout \\ Philips Research, Eindhoven \\ jettie.hoonhout@philips.com

\section{David Lamas} \\ Interaction Design Laboratory \\ Tallinn University \\ david.lamas@tlu.ee \\ Effie Law \\ Department of Computer Science \\ University of Leicester \\ elaw@mcs.le.ac.uk
}

Permission to make digital or hard copies of part or all of this work for personal or classroom use is granted without fee provided that copies are not made or distributed for profit or commercial advantage and that copies bear this notice and the full citation on the first page. Copyrights copies bear this notice and the full citation on the first page. Copyrights
for third-party components of this work must be honored. For all other for third-party components of this work must be honored.
uses, contact the Owner/Author. Copyright is held by the uses, contact the
owner/author(s)

CHI'15 Extended Abstracts, Apr 18-23, 2015, Seoul, Republic of Korea ACM 978-1-4503-3146-3/15/04.

http://dx.doi.org/10.1145/2702613.2706691

\section{Course Rationale}

As technology has supported more and more of our daily routines and activities, so Human-Computer Interaction $(\mathrm{HCI})$ research has become increasingly diverse in its methods [see, e.g., 1]. In this course we cover research methods for understanding people and interactional contexts in $\mathrm{HCI}$ problems.

We will consider the role of interdisciplinary research and mixed methods approaches in HCI: to understand the broad range of interactions people have with technology a variety of methodological approaches are usually required. These approaches have strengths and limitations that will be enhanced or exacerbated by the questions being researched and the context in which work is occurring. For instance, early efforts to study interruptions were experimental and laboratory-based. Over time our knowledge of the cognitive effects of interruptions has been augmented by richer, qualitative studies that show how interruptions are experienced in workplaces [2]. Combining approaches has endowed us with a more complete and subtle understanding of the design challenges that interruptions create.

To effectively conduct research using mixed methods it is vital to first understand the core philosophical and technical principles that underpin a particular research approach. The knowledge that produced by a particular 
Duncan Brumby is a Senior Lecturer at the UCL Interaction Centre. He has published over 50 papers, receiving peernominated awards at $\mathrm{CHI}$.

Anna Cox is a Reader at the UCL Interaction Centre. She coedited the first text book on Research Methods for HumanComputer Interaction [1].

Geraldine Fitzpatrick is a Professor at TU Wein in Austria. She has a published book and over 120 refereed journal and conference publications.

Sandy Gould is a post-doctoral research associate at the UCL Interaction Centre.

Jettie Hoonhout is a Senior Scientist at Philips Research in Eindhoven. Her research looks at user interaction technologies and user experience.

David Lamas is a Professor of Interaction Design at Tallinn University where he leads the university's Interaction Design Laboratory.

Effie Law is a Reader at the University of Leicester. She is also a visiting Senior Research Scientist of ETH Zürich. research tradition is bound by the context studied and the methods employed. What makes Interaction Science [3] a useful approach is different to what makes ethnographic approaches useful. Appreciating these nuances is critical to being able to successfully plan, run, and evaluate an HCI research project.

The course will be run by a group of leading $\mathrm{HCI}$ researchers and educators. The organizers come from a wide range of research traditions including psychology and computer science. They have worked and taught in both educational and industrial institutions around the world. One or more of the tutors will have practical research experience with each of the concepts that are covered during the course.

\section{Curriculum}

As we will be covering both quantitative and qualitative research methods the course will be run over two sessions. This will ensure sufficient time to give substantive commentary on the issues being discussed. To begin the course we will have a broad introduction to research approaches and how they have been applied in $\mathrm{HCI}$ :

- Brief history of research approaches in HCI

- Benefits and difficulties of multi-approach and multi-disciplinary research

- Ethical considerations in research with human participants

After the introduction the remainder of the course will be broadly divided between two sessions. In the first session we will focus on HCI research that takes a quantitative approach:
- $\quad$ History of controlled studies in HCI

- The purpose and benefits of controlled studies

- Experimental design

- Quantitative analysis including inferential statistics

- Quantitative studies outside the lab (e.g., field experiments)

In the second session we will focus on HCI research that takes a qualitative approach:

- History of qualitative methods in HCI

- The purpose and benefits of qualitative methods

- Ethnographic approaches

- Research techniques including interviews and experience reports

- $\quad$ Research in the wild

The course will conclude with a panel-like plenary where attendees have the opportunity to put questions and pose research dilemmas to the organizers.

\section{References}

1. Cairns, P. and Cox, A.L. Research Methods for Human-Computer Interaction. Cambridge University Press, New York, NY, USA, 2008.

2. Gould, S.J.J., Brumby, D.P., Cox, A.L., González, V., Salvucci, D., and Taatgen, N. Multitasking and interruptions: a SIG on bridging the gap between research on the micro and macro worlds. Proc. CHI'12 EA, ACM (2012), 1189-1192.

3. Howes, A., Cowan, B.R., Janssen, C.P., et al. Interaction Science SIG: Overcoming Challenges. Proc CHI'14 EA, ACM (2014), 1127-1130. 